\title{
Implementation of nursing process among nurses at Woldia Referral hospital, Northern Ethiopia: An institution-based cross-sectional study
}

Addisu Getie ( $\sim$ addisugetie@gmail.com )

Woldia University

Adam Wondmieneh

Woldia University

Teshome Gebremeskel

Woldia University

\section{Research Article}

Keywords: Nursing process, Nurse, Woldia Referral hospital

Posted Date: February 25th, 2021

DOl: https://doi.org/10.21203/rs.3.rs-226404/v1

License: (c) (1) This work is licensed under a Creative Commons Attribution 4.0 International License.

Read Full License 


\section{Abstract \\ Background}

Many countries have adopted the nursing process as a basic requirement for quality health care services, but there is a problem with its implementation in the clinical areas of many hospitals. Even though nurses accept the benefits of the nursing process, they do not use it practically. The implementation of the nursing process in Ethiopia is not well organized and developed. Many health care settings in Ethiopia demand the application of the nursing process in clinical practice.

\section{Methods}

An institutional-based, cross-sectional study design was conducted at Woldia referral hospital. A simple random sampling technique was applied to select study subjects. The data were collected using selfadministered questionnaires from February to March 2020. Binary logistic regressions were used. Then, P-value $<0.05$ was considered statistically significant in this study.

\section{Result}

This study reviled that $62.8 \%$ of nurses implemented the nursing process. Work experience greater than or equal to five years [AOR: $1.79 ; 95 \% \mathrm{Cl}(1.31-4.84)$ ], support from the administration of the organization to do the nursing process [AOR: $1.98 ; 95 \% \mathrm{Cl}(1.22-3.01)$ ], and knowledgeable nurses [AOR: $2.21 ; 95 \% \mathrm{Cl}$ (1.32-4.97)] are significantly associated with the implementation of the nursing process.

\section{Conclusion}

More than sixty present nurses implemented the nursing process. Work experience, organizational support to implement the nursing process, and knowledge were significant factors affecting the implementation of the nursing process.

\section{Introduction}

Nursing process is a holistic approach designed to nursing essence, its scientific basis, technology, main role, and humanist assumptions that encourage critical thinking, set priority, creativity, and permit solving problems in nursing practice (1). It is a widely accepted method of problem-solving and has been suggested as a scientific method to guide nursing practice and helps to quality nursing care. It is an orderly and systematic manner assessing the clients' conditions, identifying their problem, designing plans to solve a problem, initiating the plans to put in practice, implementing them, and evaluating the extent to which the plans were effective in resolving the identified problems (2). It has its steps that guide nurses in the description of holistic nursing care. The steps are assessment, nursing diagnosis, outcome 
identification, implementation, and evaluation. The nursing process decreases the hospital stay of patients and increased patient satisfaction (3).

Implementation of nursing process allows the nurse to deliver quality nursing care using a systematic and goal-directed framework. An omission in the implementation of any of the steps of the nursing process leads to less optimal nursing care (4). Poor implementation of the nursing process can result in the poor quality of nursing care, disorganization of the health service, conflicting roles among nurses, medication errors, poor disease prognosis, the dissatisfaction of customers with the care provider, increased hospital stays, and increased mortality $(2-5)$.

There was an estimated $2.9 \%$ to $3.7 \%$ of acute care hospitalizations in the USA and an estimated 44,000 to 98,000 patients die in hospital each year, with nearly half due to errors in the implementation of nursing care $(2,4)$. In Africa, many countries have adopted the nursing process as a basic requirement for quality health care services, but there is a problem with its implementation in the clinical areas of many hospitals. Studies conducted in many African countries found that while nurses generally accept the benefits of the nursing process, they do not use it practically.

In Ethiopia, nurses are the largest group of health professionals. Considering its importance in improving the quality of health care, the Ethiopian hospital's reform implementation guideline sets the nursing process as one of the core components set to improve healthcare services (8). However, in practice, it is not well implemented as evidenced by researchers done in different hospitals. These include $52.1 \%$ in Addis Ababa (9), 32.7\% in Arba Minch (10), nearly absent in Mekele (11), 35\% in selected hospitals of central and North West Zones, Tigray (12), and 37.1\% in Debre Markos referral hospital and Finote Selam hospital (13).

In general, the implementation of the nursing process by nursing practitioners in a different health care setting in Ethiopia is not well organized and developed. Currently, many health care settings in Ethiopia demand the application of the nursing process in clinical practice. This is shown by the Ethiopian Federal Minister of Health (EFMOH) prepared and distributed standardized nursing care plans and nursing care practice standards for all health care settings (14). The demand for high-quality nursing care increases day by day. This demand will be solved through the implementation of the nursing process, which is the most important tool for putting nursing knowledge into practice. As a result, all nurses should implement the nursing process, and there the level of implementation should be identified in Woldia referral hospital as there is no study conducted before on the implementation of the nursing process. Therefore, this study is designed to investigate the implementation of the nursing process and the factors affecting it among nurses working in Woldia referral hospitals.

\section{Methods}

\section{Study design and setting}


The cross-sectional study design was conducted in Woldia referral hospital in Northern Ethiopia. Woldia is a hill market town and the capital town of the North Wollo zone. It is about $521 \mathrm{Km}$ from Addis Ababa and $360 \mathrm{~km}$ from Bahirdar. The town has a total population of 75,496 of whom 37279 are females and 38,167 are males. The hospital contains 17 specialists, 45 general practitioners, 172 nurses (94 BSc and 78), and 66 midwives. The study was conducted from April to May 2020.

\section{Inclusion and exclusion criteria}

All nurses who were working in Woldia referral hospital were considered as the study population. Nurses who had at least 6 months of work experience were included in the study and nurses who were critically ill were excluded from the study. Furthermore, those nurses who were on annual and maternal leave, and those who were in short-term and long-term training during the study period were excluded from the study.

\section{Sample size determination}

The sample size was calculated based on a single population proportion formula designated as $(\mathrm{n}=$ $\left.(Z a / 2)^{2} p(1-p) / d^{2}\right)$ ); where $n=t h e$ required minimum and feasible sample size, $Z a / 2(1.96)$ : significance level at $a=0.05$ with $95 \%$ confidence interval, $p$ : the proportion of implementation of the nursing process from a previous study (0.37) (15), and d: margin of error (5\%).then, the final sample size calculated was 113 after considering $10 \%$ non-response rate.

\section{Sampling technique and sampling procedure}

Woldia Referral Hospital has seven departments. From these departments, the total sample size was allocated to each department in proportion to the number of nurses. Then, from each department, study subjects were selected by a computer-generated simple random sampling method

\section{Method of data collection}

The data were collected using pretested, structured, adopted self-administered questionnaires prepared in English. The questionnaires include information on socio-demographic characteristics, organizational and nurse's related questions, knowledge, and practice assessment questions. The questionnaires were pretested on $5 \%$ of the sample size at Dessie Referral hospital and the necessary correction was made based on the strength and weakness of the questionnaires. Furthermore, an amendment was done regarding the questionnaire format after the pretest. The data were collected by two BSc nurses and supervised by one MSc nurse. The data collectors were trained before actual data collection and the supervisors supervised the data collector closely. The nurses who scored mean and above the mean of knowledge-related questions were considered knowledgeable, whereas those who were scored below the 
mean were considered as not knowledgeable. Similarly, nurses who practiced the nursing process daily were considered as good practice, whereas those who were not practicing the nursing process at least once a day were considered under poor practice.

\section{Data processing and analysis}

After the data collection, the data template format was prepared, coded, and entered into Epidata version 4.2. Then the data were exported to SPSS version 24 for analysis. The descriptive and analytic analysis was employed to describe the percentages and distributions of the respondents for socio-demographic characteristics, organization, and nursing-related characteristics, and the factors that influence the implementation of the nursing process. Bivariate and multivariate analysis was conducted for the association of the independent variables with the dependent variable. Crude and adjusted odds ratios with the corresponding $95 \%$ confidence intervals were also computed. P-value $<0.05$ was considered statistically significant in this study. The results were presented in the form of texts and tables (10).

\section{Data quality control}

The quality of the data was assured by using; structured and validated questionnaires pretest on $5 \%$ of study subjects at Dessie referral hospital and modification and adjustment of the data collection instruments after the pretest finding, training of data collectors and supervisors for one day on the data collection instrument and data collection procedure. Furthermore, the data collectors were supervised closely by the supervisors and investigators, and the completeness of each questioner was checked by the principal investigator.

\section{Ethics approval and consent to participate}

Ethical clearance was obtained from the institutional review board of Woldia University. An official letter from the College of Health Science was written to the Woldia City Administration Health Bureau and Woldia Referral Hospital. Permission was obtained from the Woldia city administration health bureau and an official letter was given to Woldia referral hospital. Informed written consent was also obtained from all nurses. The confidentiality of the information was reassured that they were anonymous. All methods were carried out following relevant guidelines and regulations (8).

\section{Funding source}

The funding organization is Woldia University. There is no role in the development of the paper except the logistics one.

\section{Results}

Socio-demographic characteristics of the respondents 
Of the 113 respondents, $54.9 \%$ were males and $45.1 \%$ were females. The age of the respondents was ranged between 17 and 45 years with a median age of 26. The work experience of nurses varies from one to twenty-three years, while the majority lies in less than five years with a mean of 4.4 years. The majority, $53.1 \%$ of the participants were diploma nurses (Table 1 ).

\section{Organizational and nurse related factors}

Of the total respondents, $68.1 \%$ worked overtime; of these, $83.3 \%$ of nurses were dissatisfied with their payment. Forty-seven $(41.6 \%)$ of them described their working place as it were stressful and $33.6 \%$ of nurses thought the reason for patients turning over was a poor understanding of modern medicine (Table 2).

\section{Nurse's knowledge and practice of the nursing process}

The results of this study showed that $62.8 \%$ of nurses had a good practice of the nursing process and $54 \%$ were knowledgeable regarding the implementation of the nursing process. Eighty-nine respondents knew all components of the nursing process and $63.3 \%$ differentiated nursing diagnosis from medical diagnosis (Table 3 ).

\section{Factors affecting the implementation of the nursing process}

This study reviled that the implementation of the nursing process among nurses was affected by the working experience. Nurses who had work experience of greater or equal to five years were 1.79 times more likely to implement the nursing process than those who had work experience less than five years [AOR: $1.79 ; 95 \% \mathrm{Cl}(1.31-4.84)$ ]. Similarly, nurses who got Support from the administration of the organization to do the nursing process were 1.98 times more likely to implement the nursing process face than their counterparts [AOR: 1.98; $95 \% \mathrm{Cl}(1.22-3.01)]$. The implementation of the nursing process is also affected by the knowledge of nurses regarding the nursing process. Nurses who had good knowledge about the nursing process were 2.21 times more likely to implement the nursing process than nurses who had poor knowledge about the nursing process [AOR: 2.21; 95\% $\mathrm{Cl}(1.32-4.97)$ ] (Table 4).

\section{Discussion}

This study revealed that $62.8 \%$ of nurses were implementing nursing process and the rest. This is not enough as compared to the demand of nursing process. This might be due to the reason that nurses working in Woldia referral hospital had work overload. However, the result of this study is higher than studies conducted Harar (48.9\%) (17), Addis Ababa (52.1\%) (9), and Debre Markos and Finote Selam hospitals $(37.1 \%)$ (13). This variation might be due to the difference in the level of nurse's knowledge about nursing process, training availability, and follow-up on the implementation of nursing process. Thus, nurses working at hospitals found nearby universities believed to have better knowledge to practice nursing process. The possible reason is that there will be continuous follow-up and training on the implementation of nursing process. It might be also due to the different study years, which the previous 
studies were conducted before five years when the issue of nursing process was not emphasized. Conversely, the prevalence of implementation of nursing process in this study is lower than studies conducted in Nigeria (64.22\%) (16) and Brazil (98.7\%) (17), This substantial difference might be due to the difference in socio-demographic factors of nurses, patient flow, nurse and patient ratio, and organizational facilities that can help to implement nursing process. The additional possible reason may be due to differences in the study setting, availability of resources, and technological advancements. Since Ethiopia is one of the low-income countries, there is a shortage of nurses, lack of training, and limited resources which deters the implementation of nursing process.

Regarding the level of knowledge, $54 \%$ of nurses were knowledgeable and the remaining $46 \%$ were not knowledgeable about the nursing process, which lower than the finding of a study conducted in Harar Regional Hospital, which $87.7 \%$ of the respondents were knowledgeable, and $14.4 \%$ were not knowledgeable (17). However, it is higher than the findings of a study conducted in Mekelle Hospitals, where nearly $90 \%$ of nurses had poor knowledge and the remaining $10 \%$ had fair knowledge (11). It is also inconsistent with a study done in Arba Minch, where $23.34 \%$ of nurses were highly knowledgeable, $44.9 \%$ were moderately knowledgeable, and $31.63 \%$ were poorly knowledgeable (10). It varies with the finding of a study conducted at Debre Markos and Finote Selam hospitals, where $58.1 \%$ were highly knowledgeable, $30.6 \%$ moderately knowledgeable, and the remaining $11.3 \%$ poorly knowledgeable. The finding of the current study also disagrees with a study done in Addis Ababa, where $16.1 \%$ of participants were highly knowledgeable, $52.6 \%$ moderately knowledgeable, and $31.2 \%$ poorly knowledgeable $(9,13)$.

The variation may be due to differences in the study setting. In the previous studies, all participants were from university hospitals, where nurses may have the opportunity to be trained about nursing process.

The level of knowledge in this study is inconsistent with a study conducted in Nigeria, where $92 \%$ of nurses had good knowledge, while only $8 \%$ of participants had poor knowledge about nursing process (16). Similarly, it is inconsistent with a study done in Saudi Arabia, where $94.6 \%$ of participants had good knowledge regarding nursing process. The possible justification is that the variation in work experience, support from the organization, lack of training, and nurse to patient ratio. Nurses who had experience of five years and above were nearly two times more likely to implement the nursing process than their counterparts. This is because experienced nurses build knowledge and a positive attitude towards the nursing process, which directly motivates them to implement the nursing process. Nurses who got support from the hospital administration to do the nursing process were more likely to implement the nursing process due to initiatives from the organizations. The findings of this study also showed that nurses who had good knowledge were 2.21 times more likely to implement the nursing process. This is because knowledgeable nurses can easily understand how a patient gets improvement, which is due to the practicing of the nursing process.

\section{Conclusion}


In this study, more than sixty present nurses implemented the nursing process. Work experience of nurses less than five years, absence of organizational support of nurses to implement the nursing process, and poor knowledge of nurses about the nursing process were significant factors affecting the implementation of the nursing process. Having work experience of fewer than five years may cause the nurse to have poor knowledge, which further deters the implementation of the nursing process. If the organization does not support the nurse to implement the nursing process, it will not focus on the practice and lead to poor implementation of the nursing process. Therefore, the nurse and nurse educator should update their knowledge on the nursing process, theoretical aspects, as well as practical aspects, especially for new graduate nurses. There should be also orientation and training about the nursing process. Furthermore, nurses' patient care knowledge in general and the nursing process, in particular, should be evaluated and monitored periodically.

\section{Limitations Of The Study}

It was impossible to establish a cause-and-effect relationship as the study design was a cross-sectional study. Due to the small sample size, the result might not be representative of all nurses working in Ethiopia.

\section{Abbreviations}

AOR: Adjusted Odds Ratio, BSc: Bachelor of Science, Cl: Confidence Interval, COR: Crude Odds Ratio, EFMOH: Ethiopian Federal Minister of Health, SPSS: Satirical Package for Social Science.

\section{Declarations}

\section{Ethical approval and consent form}

Ethical clearance was obtained from the Institutional Review Board of Woldia University. An official letter was written to the Woldia referral hospital. Permission was obtained from the administrative staff of the hospital. Verbal informed consent was approved by the Institutional Review Board of Woldia University and the data were collected after taking informed oral consent from study participants. The study participants were also informed of the attainment of confidentiality and anonymity or any identifiers.

\section{Consent for publication}

Not applicable

\section{Availability of dataset and materials}

The datasets used for analysis are available from the corresponding author on reasonable request.

\section{Competing interests}


The authors declare that they have no competing interests

\section{Funding}

Woldia University: The funder has no role in the study design, data collection, analysis, and publication

\section{Authors' contributions}

AG. Wrote the main manuscript text, AG., and AW. Wrote the methodology and the discussion section. AG, AW, and TG. Prepared tables. All authors contributed to data analysis, drafting or revising the article, have agreed on the journal to which the article will be submitted, gave final approval of the version to be published, and agree to be accountable for all aspects of the work.

\section{Acknowledgments}

We are grateful to thank the study participants and hospital administrators for their willing full participation in the timely fashion

\section{References}

1. Ledesma-Delgado $M$, Mendes MMR. The nursing process is presented as routine care actions: building its meaning from the clinical nurses' perspective. Revista Latino-Americana, 2009; 17(3):328-34.

2. Pokorski S, Moraes MA, Chiarelli R, Costanzi AP, Rabelo ER. Nursing process: from literature to practice. What are we doing? Revista Latino-Americana de Enfermagem. 2009; 17(3):302-7.

3. Adejumo P, Olaogun A. Nursing Process: a tool for a holistic approach to nursing care. West African Journal of Nursing. 2009; 20(1):34-9.

4. Reppetto MÂ, Souza MFd. Evaluation of nursing care systematization through the phases of nursing process performance and registration in a teaching hospital. Revista Brasileira 2005; 58(3):325-9.

5. Freitas MCd, Queiroz TA, Souza JAVd. The nursing process according to the view of nurses from a maternity. Revista brasileira de enfermagem. 2007; 60 (2):207-12.

6. Edet A, Mgbekem M, Edet O. Professional Nurses' Perception and Utilization of the nursing process at the University of Calabar Teaching Hospital (UCTH), Calabar, Nigeria. BSc thesis https://www research gate net/publication/258422875. 2012.

7. Sabona E, Irinoye O, Kamazi D, Uys L, Ofi B, Cassimjee R. The perception on, and use of, the nursing process in four African Countries. Afr J Nurs Midwifery. 2005;6(1):67-77.

8. Ethiopian Hospital Reform Implementation Guidelines. Volume 1. Chapter 6 Nursing Care Standards. 2010.

9. Mulugeta Aseratie1 RMaMM. Assessment of Factors Affecting Implementation of Nursing Process AmongNurses in Selected Governmental Hospitals, Addis Ababa, Ethiopia; Cross-Sectional Study. 2014. 
10. Shewangizaw Z, Mersha A. Determinants towards the implementation of the nursing process. Am J Nurs. 2015; 4 (3):45-9.

11. Hagos F, Alemseged F, Balcha F, Berhe S, Aregay A. Application of nursing process and its affecting factors among nurses working in Mekelle zone hospitals, Northern Ethiopia. Nursing research and practice. 2014.

12. Zeray Baraki1* FG, Kalayou Kidanu2, Hadgu Gerensea1, Dejen Gezehgne3, and Hafte Teklay4. Ethiopian Hospital Reform Implementation Guidelines. Volume 1. Chapter 6 Nursing Care Standards. 2015.

13. Nurilign Abebe1* HAaMA. The Implementation of Nursing Process and Associated Factors among NursesWorking in Debremarkos and Finoteselam Hospitals, Northwest Ethiopia, 2013.

14. Nursing care practice standards, Reference manual for nurses, and health care managers in Ethiopia. Health MO.Addis Abeba, editor. 2011.

15. Queiroz OCAd, Sant'Ana RSE, Oliveira SdC, Moinhos AS, Santos LS. Nurse's perception in front of the implementation of nursing diagnosis and prescription. Journal of Nursing UFPE on line [JNUOL/DOI: 105205/01012007]. 2012; 6(6):1346-51.

16. Nursing Process among Nurses - Factors Affecting Implementation. 2015.

17. Negesa1 GABTNHL. The practice of the nursing process and associated factors among nurses in public hospitals of Harar people national regional state in 2017.

\section{Tables}

Table 1: Socio-demographic characteristics of nurses working in Woldia Referral hospital, Northern Ethiopia, 2020. 


\begin{tabular}{|c|c|c|c|c|}
\hline Characteristics & & & Frequency & Percentage (\%) \\
\hline \multirow[b]{2}{*}{ Sex } & Male & 62 & & 54.9 \\
\hline & Female & & 51 & 45.1 \\
\hline \multirow[t]{2}{*}{ Age } & $<29$ & 89 & & 78.8 \\
\hline & $>29$ & 24 & & 21.2 \\
\hline \multirow[t]{3}{*}{ Marital status } & Single & 76 & & 67.3 \\
\hline & Married & 32 & & 28.3 \\
\hline & Widowed & 5 & & 4.4 \\
\hline \multirow[t]{2}{*}{ Educational status } & BSc & 53 & & 46.9 \\
\hline & Diploma & 60 & & 53.1 \\
\hline \multirow[t]{2}{*}{ Working experience } & $<5$ years & 60 & & 53.1 \\
\hline & $\geq 5$ years & 53 & & 46.9 \\
\hline \multirow[t]{4}{*}{ Working hours/day } & $<8$ hours & 19 & & 16.8 \\
\hline & 8 hours & 84 & & 74.3 \\
\hline & 12 hours & 7 & & 6.2 \\
\hline & $>12$ hours & 3 & & 2.7 \\
\hline
\end{tabular}

Table 2: Organizational and nurse's related factors for the implementation of the nursing process in Woldia referral hospital, Northern Ethiopia, 2020. 


\begin{tabular}{|c|c|c|c|}
\hline Variables & Responses & Frequency & $\begin{array}{l}\text { Percentage } \\
(\%)\end{array}$ \\
\hline \multirow[b]{2}{*}{ Overtime work } & Yes & 77 & 68.1 \\
\hline & No & 36 & 31.9 \\
\hline \multirow[b]{2}{*}{ Satisfied with payment } & Yes & 13 & 16.9 \\
\hline & No & 64 & 83.1 \\
\hline \multirow{3}{*}{ Workplace } & Stressful & 47 & 41.6 \\
\hline & Negligent at a time & 40 & 35.4 \\
\hline & Disorganized & 26 & 23 \\
\hline \multirow{3}{*}{ Effect of staff turnover } & Decreasing productivity & 27 & 23.9 \\
\hline & Disorganized service delivery & 61 & 54 \\
\hline & Decrease spread of knowledge & 25 & 22.1 \\
\hline \multirow{5}{*}{$\begin{array}{l}\text { Methods used to make work } \\
\text { visible }\end{array}$} & Recording every activity performed & 42 & 37.2 \\
\hline & Using the nursing process & 44 & 38.9 \\
\hline & Reporting to the supervisors & 8 & 7.1 \\
\hline & Working on a patient problem & 16 & 14.2 \\
\hline & Nothing used & 3 & 2.7 \\
\hline \multirow{4}{*}{$\begin{array}{l}\text { The major reason for patient } \\
\text { turnover }\end{array}$} & $\begin{array}{l}\text { Poor understanding of modern } \\
\text { medicine }\end{array}$ & 38 & 33.6 \\
\hline & Poor economic status & 55 & 48.7 \\
\hline & Long time required to get the service & 19 & 16.8 \\
\hline & If they have incurable diseases & 1 & 0.9 \\
\hline \multirow{4}{*}{$\begin{array}{l}\text { How it influences your nursing } \\
\text { care delivery? }\end{array}$} & $\begin{array}{l}\text { Discharge before completing } \\
\text { interventions }\end{array}$ & 27 & 23.9 \\
\hline & $\begin{array}{l}\text { Not cooperative for the care that } \\
\text { you provide }\end{array}$ & 19 & 16.8 \\
\hline & Inability to collect required materials & 32 & 28.3 \\
\hline & $\begin{array}{l}\text { Complicated cases that patients } \\
\text { presented with }\end{array}$ & 35 & 31 \\
\hline
\end{tabular}

Table 3: Nurse's knowledge about the implementation of the nursing process at Woldia referral hospital, Northern Ethiopia, 2020. 


\begin{tabular}{|lll|}
\hline Variables & $\begin{array}{l}\text { Correct } \\
\text { No (\%) }\end{array}$ & $\begin{array}{l}\text { Incorrect } \\
\text { No (\%) }\end{array}$ \\
\hline Component of nursing process (steps of nursing process) & $\begin{array}{l}89 \\
(78.8 \%)\end{array}$ & $24(21.2 \%)$ \\
\hline Gordon approach & $66(58.4 \%)$ & $47(41.6 \%)$ \\
\hline $\begin{array}{l}\text { A nursing diagnosis is better to solve a patient's problem with diabetes } \\
\text { mellitus chronic complication in the future? }\end{array}$ & $30(26.5 \%)$ & $83(73.5 \%)$ \\
\hline The difference between the nursing process and medical approach & $72(63.7 \%)$ & $41(36.3 \%)$ \\
\hline Better accomplishment of nursing process & $65(57.5 \%)$ & $48(42.5 \%)$ \\
\hline Activities to be performed in the planning phase of the nursing process & $25(22.1 \%)$ & $88(77.9 \%)$ \\
\hline $\begin{array}{l}\text { In the implementation step of the nursing process, a nurse is expected to } \\
\text { perform }\end{array}$ & $53(46.9 \%)$ & $60(53.1 \%)$ \\
\hline Guide for evaluation of nurses performance in nursing process & $49(43.4 \%)$ & $64(56.6 \%)$ \\
\hline $\begin{array}{l}\text { Identify the problem, etiology and sign/symptom of nursing diagnosis } \\
\text { Write full nursing diagnosis }\end{array}$ & $87(77 \%)$ & $26(23 \%)$ \\
\hline
\end{tabular}

Table 4: Bivariate and multivariable analysis of the implementation of the nursing process among nurses working at Woldia referral hospital, Northern Ethiopia, 2020. 


\begin{tabular}{|c|c|c|c|c|c|}
\hline \multirow[t]{2}{*}{ Variable } & \multirow[t]{2}{*}{ Response } & \multicolumn{2}{|c|}{ Practice } & \multirow{2}{*}{$\begin{array}{l}\operatorname{coR}(95 \% \\
\mathrm{Cl})\end{array}$} & \multirow{2}{*}{$\begin{array}{l}\mathrm{AOR}(95 \% \\
\mathrm{Cl})\end{array}$} \\
\hline & & Good & Poor & & \\
\hline \multirow[t]{3}{*}{ Marital status } & Single & 48 & 28 & 1 & 1 \\
\hline & Married & 22 & 10 & $\begin{array}{l}1.28 \\
(0.53- \\
3.09)\end{array}$ & $\begin{array}{l}0.99 \\
(0.29- \\
3.38)\end{array}$ \\
\hline & Divorced & 1 & 4 & $\begin{array}{l}0.15 \\
(0.02- \\
1.37)\end{array}$ & $\begin{array}{l}0.42 \\
(0.03- \\
7.00)\end{array}$ \\
\hline \multirow[t]{2}{*}{ Sex } & Male & 43 & 19 & $\begin{array}{l}1.4(0.86- \\
4.02)\end{array}$ & $\begin{array}{l}1.20 \\
(0.66- \\
4.89)\end{array}$ \\
\hline & Female & 28 & 23 & 1 & 1 \\
\hline \multirow[t]{2}{*}{ Work experience } & $<5$ & 19 & 41 & 1 & 1 \\
\hline & $\geq 5$ & 42 & 11 & $\begin{array}{l}2.77 \\
(1.95- \\
4.54)\end{array}$ & $\begin{array}{l}1.79 \\
(1.31- \\
4.84)\end{array}$ \\
\hline \multirow[t]{4}{*}{ Patient give care per day } & $<5$ & 4 & 9 & 1 & 1 \\
\hline & $5-10$ & 30 & 18 & $\begin{array}{l}0.13 \\
(0.03- \\
0.55)\end{array}$ & $\begin{array}{l}2.27 \\
(0.45- \\
11.46)\end{array}$ \\
\hline & $10-15$ & 13 & 8 & $\begin{array}{l}0.49 \\
(0.17- \\
1.36)\end{array}$ & $\begin{array}{l}1.96 \\
(0.33- \\
11.47)\end{array}$ \\
\hline & $>15$ & 24 & 7 & $\begin{array}{l}0.47 \\
(0.14- \\
1.60)\end{array}$ & $\begin{array}{l}3.42 \\
(0.56- \\
20.75)\end{array}$ \\
\hline \multirow[t]{2}{*}{ Equipment to implement nursing care } & Yes & 31 & 25 & $\begin{array}{l}0.73 \\
(0.24- \\
1.14)\end{array}$ & $\begin{array}{l}0.74 \\
(0.27- \\
2.04)\end{array}$ \\
\hline & No & 40 & 17 & 1 & 1 \\
\hline \multirow[t]{2}{*}{$\begin{array}{l}\text { Support from the administration to do } \\
\text { nursing process }\end{array}$} & yes & 58 & 23 & $\begin{array}{l}2.32 \\
(1.23- \\
4.39)\end{array}$ & $\begin{array}{l}1.98 \\
(1.22- \\
3.01)\end{array}$ \\
\hline & No & 11 & 21 & 1 & 1 \\
\hline \multirow[t]{2}{*}{$\begin{array}{l}\text { Monitoring and evaluation for } \\
\text { application of nursing process }\end{array}$} & Ye & 58 & 30 & $\begin{array}{l}1.63 \\
(0.73- \\
4.39)\end{array}$ & $\begin{array}{l}1.08 \\
(0.57- \\
5.50)\end{array}$ \\
\hline & No & 13 & 12 & 1 & 1 \\
\hline
\end{tabular}




\begin{tabular}{|c|c|c|c|c|c|}
\hline \multirow[t]{2}{*}{ Worked overtime } & Yes & 52 & 25 & $\begin{array}{l}1.57 \\
(0.83- \\
4.18)\end{array}$ & $\begin{array}{l}1.40 \\
(0.50- \\
3.87)\end{array}$ \\
\hline & No & 19 & 17 & 1 & 1 \\
\hline \multirow[t]{2}{*}{ Knowledge } & Knowledgeable & 46 & 6 & $\begin{array}{l}2.64 \\
(1.28 \\
-6.19)\end{array}$ & $\begin{array}{l}2.21 \\
(1.32- \\
4.97)\end{array}$ \\
\hline & Not knowledge & 25 & 36 & 1 & 1 \\
\hline
\end{tabular}

AOR; Adjusted Odds Ratio, Cl; Confidence Interval, COR; Crude Odds Ratio

\section{Supplementary Files}

This is a list of supplementary files associated with this preprint. Click to download.

- questiononnursingprocess.pdf 